\title{
The experiences of new graduate midwives working in midwifery continuity of care models in Australia
}

\author{
Allison M. Cummins, RM MA(ed) PhD candidate (Lecturer in Midwifery)*, \\ E. Denney-Wilson (Senior Lecturer, Associate Professor), C.S.E. Homer (Professor of \\ Midwifery, Associate Dean - International and Development) \\ Faculty of Health, University of Technology, Broadway, NSW 2007, Australia
}

\section{A R T I C L E I N F O}

\section{Article history:}

Received 26 August 2014

Received in revised form

18 November 2014

Accepted 31 December 2014

\section{Keywords:}

New graduate midwives

Midwifery continuity of care models

Skill consolidation

Confidence

Interpersonal relationships

\begin{abstract}
A B S T R A C T
Background: midwifery continuity of care has been shown to be beneficial to women through reducing interventions and other maternal and neonatal morbidity. In Australia, numerous government reports recognise the importance of midwifery models of care that provide continuity. Given the benefits, midwives, including new graduate midwives, should have the opportunity to work in these models of care. Historically, new graduates have been required to have a number of years' experience before they are able to work in these models of care although a small number have been able to move into these models as new graduates. Aim: to explore the experiences of the new graduate midwives who have worked in midwifery continuity of care, in particular, the support they received; and, to establish the facilitators and barriers to the expansion of new graduate positions in midwifery continuity of care models.

Method: a qualitative descriptive study was undertaken framed by the concept of continuity of care.

Findings: the new graduate midwives valued the relationship with the women and with the group of midwives they worked alongside. The ability to develop trusting relationships, consolidate skills and knowledge, be supported by the group and finally feeling prepared to work in midwifery continuity of care from their degree were all sub-themes. All of these factors led to the participants feeling as though they were 'becoming a real midwife'.

Conclusions: this is the first study to demonstrate that new graduate midwives value working in midwifery continuity of care - they felt well prepared to work in this way from their degree and were supported by midwives they worked alongside. The participants reported having more confidence to practice when they have a relationship with the woman, as occurs in these models.
\end{abstract}

(c) 2015 Elsevier Ltd. All rights reserved.

\section{Introduction}

Midwifery continuity of care is defined as "care provided to women throughout pregnancy, birth and the early parenting period from one midwife or a small group of midwives' (Sandall et al., 2013). This way of providing care has been shown to be beneficial to women and babies (Homer et al., 2001; Page, 2003; Hodnett, 2008; Pairman et al., 2010; Hartz et al., 2011; Hodnett et al., 2011; McLachlan et al., 2012; Sandall et al., 2013). Midwives and women have also reported high rates of satisfaction with midwifery continuity of care models (Fereday et al., 2009; Collins et al., 2010). In Australia, numerous government reports have recognised the importance of midwifery continuity of care

\footnotetext{
* Corresponding author.

E-mail address: allison.cummins@uts.edu.au (A.M. Cummins).
}

models and have recommended widespread implementation (Australian Government Department of Health and Ageing, 2009; New South Wales Health, 2010).

Midwifery continuity of care can be organised in a variety of ways. One-to-one midwifery care refers to having a primary midwife who cares for 35-40 women a year (Page, 2003; Homer et al., 2008). Often midwives work together with a second midwife to ensure they have some time off with the second midwife being available if the primary midwife is unavailable to ensure some adequate life/work balance (Page, 2003). Midwifery group practice (MGP) generally refers to groups of three to four midwives who have a caseload of women with the flexibility to have rostered time off including sick and annual leave with backup from one or more midwives in the group (Homer et al., 2008). A third model providing a level of continuity is team midwifery. Team midwifery generally comprises six to eight midwives providing care often on 
a rostered system (Homer et al., 2008). When midwives begin to work in a midwifery continuity of care model they are provided with a period of orientation and sometimes, initially a reduced caseload. Midwifery continuity of care models often cater for women who are predominantly healthy however increasingly, all-risk models are being implemented in collaboration with obstetricians (Australian Nursing \& Midwifery Council, 2008). Various models exist throughout Australia with limited opportunities for new graduate midwives to work in continuity of care. The participants in this study were employed in models ranging from one to one midwifery to small teams of midwives working an on-call roster to provide care for approximately 40 women a year.

A new graduate midwife is one working in their first or second year of practice post initial registration. Historically, most new graduate midwives in Australia undertake a transition support programme that require the new graduate midwife to rotate through antenatal clinics, birth suite and postnatal wards over a 12 month period (Clements et al., 2013). A qualitative study reporting on newly graduated midwives' experiences of a similar model in the United Kingdom (Foster and Ashwin, 2014) found the participants did not have enough time in any one hospital area before rotating to another where they had to relearn skills. It is not clear whether this style of transitional support is appropriate or necessary for new graduates who desire to work in continuity of care models (Clements et al., 2013).

In Australia, midwives are prepared to work in continuity of care models as students; an essential part of the midwifery curriculum is to 'follow through' a number of women during their programme (Gray et al., 2012; Australian Nursing and Midwifery Council, 2010). This requirement is based on the evidence that these models have improved outcomes for women and their families. Despite this, when positions are advertised for continuity of care models, the criteria often includes a minimum two years' experience, prohibiting new graduate midwives from applying.

Despite obstacles to new graduates entering midwifery continuity of care, there are small numbers working in this way around Australia. In order to support wider implementation of such opportunities, we were interested in their experiences. This is the first study in Australia, to focus on new graduate midwives working in midwifery continuity of care. The aim of the study was to explore the experiences of these new graduate midwives, in particular, to examine the support they received and to establish the facilitators and barriers to the expansion of new graduate positions in midwifery continuity of care models.

Ethical approval was sought and granted by the university ethics committee (HREC Approval Number: 2012000328).

\section{Methods}

A qualitative descriptive approach was used to describe and explore the new graduate's experiences of working in midwifery continuity of care. The exploration was based on the interest in, and understanding of, the 'who, what and where' of their experiences (Sandelowski, 2000, p. 338). Qualitative descriptive research is a useful form of rigorous and credible enquiry in situations where there is little knowledge and is particularly useful to describe how people feel about an event (Sandelowski, 2000; Avis, 2003; Hughes and Fraser, 2011). This study addresses each area of the who, what and where (Sandelowski, 2010) of new graduate experiences of working in midwifery continuity of care.

\section{Sample}

Purposive sampling recruited newly graduated midwives working within their first or second year of practice in a midwifery continuity of care model. Purposive sampling is used when the population of interest is small (Minichiello et al., 2004). The difficulties in recruitment meant the authors needed to find midwifery models of care that employed new graduates. The first author attended a midwifery 'models of care' conference in South Australia with the intention of recruiting new graduate midwives to participate in the study. The purposive sampling then became a process of snowball sampling where participants were asked if they knew any other new graduate midwives working in continuity of care models. Both these sampling methods were approved by the university human research ethics committee. Using this process, 13 newly graduated midwives were recruited. From our professional networks, we estimate this to be approximately $50 \%$ of the new graduate midwives working in midwifery continuity of care models across Australia.

The 13 participants (Table 1 ) were newly graduated midwives in either their first or second year of practice after graduation. Pseudonyms have been used to protect the identity of the participants and to highlight the repletion of responses and to show when different participants had similar experiences. Participants were aged 21-46 years and employed in a variety of settings from tertiary referral hospitals to stand-alone birth centres. Eleven worked full time with one part-time (six shifts a fortnight partnering with another midwife to provide a caseload practice) and one was not working at the time of the interview. Twelve had completed the direct-entry Bachelor of Midwifery program, three from South Australia, two from the Australian Capital Territory (ACT) and eight from New South Wales (NSW). One completed a Graduate Diploma in Midwifery in NSW, a postgraduate course for registered nurses that leads to registration as a midwife. Eleven had started in a new graduate transition programme with two commencing in midwifery continuity of care immediately after graduation. Three had the continuity of care programme incorporated as part of their new graduate programme and were then employed in that model without returning to the rotation programme through the various maternity wards.

\section{Data collection}

Data were collected via semi-structured interviews. Participants were offered a choice of the interview being conducted face-to-face, via telephone or skype. One researcher (the first author, who is also a midwife) conducted all the interviews. A list of open-ended questions were chosen that guided the interview but provided flexibility to respond to the participant (Box 1).

Table 1

Demographic details of the participants - location, year of gradation, programme, working status and age.

\begin{tabular}{|c|c|c|c|c|c|}
\hline No & State & $\begin{array}{c}\text { Year } \\
\text { graduated }\end{array}$ & Programme & $\begin{array}{l}\text { Working } \\
\text { fulltime }\end{array}$ & $\begin{array}{c}\text { Age } \\
\text { range* }^{*}\end{array}$ \\
\hline 1 & South Australia & 2012 & BMid & Yes & $36-40$ \\
\hline 2 & New South Wales & 2011 & BMid & Yes & $26-30$ \\
\hline 3 & New South Wales & 2011 & BMid & Yes & $20-25$ \\
\hline 4 & New South Wales & 2010 & BMid & Yes & $20-25$ \\
\hline 5 & South Australia & 2011 & BMid & Yes & $31-35$ \\
\hline 6 & South Australia & 2011 & BMid & No & $31-35$ \\
\hline 7 & $\begin{array}{l}\text { Australian Capital } \\
\text { Territory }\end{array}$ & 2012 & BMid & Yes & $25-30$ \\
\hline 8 & New South Wales & 2011 & BMid & No & $31-35$ \\
\hline 9 & $\begin{array}{l}\text { Australian Capital } \\
\text { Territory }\end{array}$ & 2011 & BMid & Yes & $20-25$ \\
\hline 10 & New South Wales & 2011 & BMid & Yes & $46-50$ \\
\hline 11 & New South Wales & 2011 & BMid & No & $36-40$ \\
\hline 12 & New South Wales & 2011 & BMid & Yes & $26-30$ \\
\hline 13 & New South Wales & 2012 & GradDipM & Yes & $36-40$ \\
\hline
\end{tabular}

BMid $=$ Bachelor of Midwifery (direct entry); GradDipM=Graduate Diploma in Midwifery.

* Ranges have been given to protect anonymity. 


\section{Box 1 \\ Questions \\ Why did you choose to work in midwifery continuity of care? \\ What is your experience of working in continuity of care? What did you aim to achieve in your transitional year/s? How did you achieve what you planned? \\ What has been the best part of working in midwifery continuity of care?}

The questions gave the interview some structure but were not always asked in this order to enable flexibility. Using preformed questions/prompts can give an interview some structure (Rees, 2012). The questions were designed to explore the barriers and facilitators to working in midwifery continuity of care models. In addition, we were interested in the positive aspects and levels of continuity of care in line with the theory around continuity of care (Saultz, 2003).

The participants were from different parts of the country making face-to-face interviews difficult; hence phone interviews were the main mode of data collection. Burns et al. (2012) described the insider/outsider dilemmas experienced by a researcher during observations undertaken on a maternity ward by a midwife researcher. A similar concept had the potential to occur in this study, as the interviewer was also a midwife with extensive clinical experience and a sound understanding of continuity of midwifery care. The interviewer was in a unique position to identify the issues raised by the participants with the potential for the blurring of boundaries as described by Burns et al. (2012). The interviewer needed to position herself as a researcher rather than a colleague. Having a team of three researchers, assisted with defining boundaries as the other team members only read deidentified data and therefore were outsiders to provide balance.

The interviews were audio recorded and transcribed verbatim. The researcher transcribed three of the interviews and the remainder were transcribed by a professional transcriber. The transcripts were all read while listening to the audio recordings to ensure transcription accuracy.

\section{Analysis}

Thematic analysis was used to capture important concepts in relation to the research question (Braun and Clarke, 2006). The data were read and entered into the software program NVIVO (Minichiello et al., 2004). A process of coding into groups known as nodes identified certain themes. The themes were initially descriptive and once the researcher began to write and reread the data, a deeper analysis occurred which was framed by the concept of continuity of care (Saultz, 2003).

Saultz (2003) developed hierarchical definitions of continuity of care. The base of this hierarchy is informational continuity where medical and social information about the person is available to a number of care providers ensuring safe communication about a person's particular situation (Saultz, 2003). The next level of continuity is defined as longitudinal where information is shared in a familiar place by an organised team of care providers (Saultz, 2003). The highest level of continuity proposed is interpersonal based on the philosophical underpinning that continuity of care is about the relationship between the care provider and the person over time (Saultz, 2003). The theory of continuity of care was developed by Saultz (2003) and applied to midwifery by Homer et al. (2008). The interpersonal (Homer et al., 2008)
INTERPERSONAL CONTINUITY OF CARE

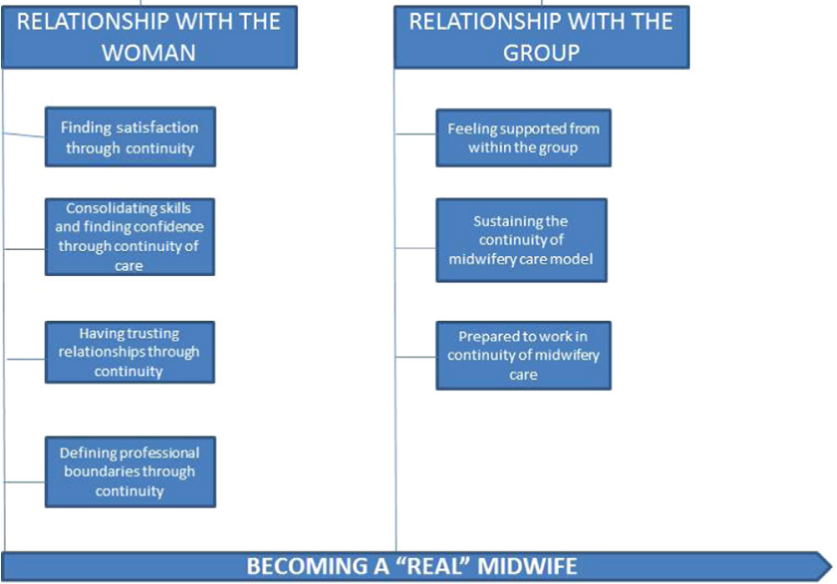

Fig. 1. Broad themes and sub-themes and the relationship with continuity of care.

definition is most appropriate based on the philosophical underpinning that continuity of care is about the relationship between the woman and the midwife over time. Themes and sub-themes were then identified and discussed with the two other co-authors, subsequent analysis, themes and subthemes were developed within the framework of continuity of care.

\section{Findings}

The overarching concept was interpersonal continuity of care (Saultz, 2003) with two broad themes, that is, 'the relationship with the woman' and 'the relationship with the group'. There were further subthemes that led the participants to report they were 'becoming a real midwife' (Fig. 1).

\section{The relationship with the woman}

The relationship with the woman was valued in so many aspects of the care provided by the participants. As Judy stated, 'I really love the relationship' and 'it is food for my soul'.

The participants who had worked in a standard transition support programme prior to working in continuity of care compared the two approaches. The relationship with the woman was highly valued and contributed to the provision of quality care. Samantha stated 'now I can really spend time with women'. Samantha went on to say 'as I get to know the woman, I think they get better care' and 'women get better care' (Alice). Candice and other new graduates felt that 'the outcomes are better' compared with women they cared for when working in the standard transition support programme. The participants did not explain which outcomes were better but went on to discuss issues like normal birth and increased rates of breast feeding suggesting they were valued. The relationship with women enabled them to promote normal birth, provide more effective care and was highly satisfying. For example, Samantha described 'feeling happier' working in a continuity model.

\section{Finding satisfaction with continuity}

Working in continuity of care as a new graduate was highly satisfying. Bridget reported the satisfaction of 'seeing a woman being empowered' as 'so rewarding'. She went onto describe how 
she felt 'lucky to know the whole woman' and 'having a relationship with the woman is a position of privilege'. Christine described herself as 'one of those people that really enjoys having relationships' and therefore working in this way as a new graduate really suited her.

Being satisfied working in midwifery continuity of care was a two-way interaction. Lisbeth illustrates this point saying that the 'woman is so happy that you are there' and Ness, 'they [the women] were always happy to have me there'. Building a relationship between the woman and the midwife, for example, 'getting to know the woman I am caring for made me feel more effective as a midwife' was a crucial component of care. They felt that continuity of carer provided a satisfying experience for the woman, as she knew her midwife, described here:

I loved the satisfaction that women got from having that trust in the one carer also the satisfaction I got and the midwives would get from seeing them from the beginning to end (Lisbeth)

The participants used positive emotional phrases to discuss the benefits of midwifery continuity of care. Hattie said she 'gets tingles every time she sees a woman starting her mothering journey' and Lisbeth stated she is 'happy all the time' when she knows the woman. These emotional accounts highlight the satisfaction of being in a position to develop trusting relationship with women through continuity of carer and this was valuable for the new graduates.

\section{Consolidating skills and finding confidence through continuity of care}

The relationship with the woman helped the new graduates learn and consolidate skills. For example, Lisbeth said 'I found I learnt a lot more because I could see the story unfold and it made more sense to me' and Bridget also explained 'over time you get to see her pregnancy unfold together with her family'. When the midwife knows the woman then she can be quietly present at a birth without having to build rapport as Christine said 'seeing the whole process is easier than just snapshots of someone who has just walked in, in labour'. In addition, the relationship with the woman helped to increase their confidence. The 'unfolding' of the woman's pregnancy revealed new learning opportunities to consolidate skills and increase their confidence. For example, Alice described how knowing the woman, seeing her again rather than just a 'snapshot made me feel more effective as a midwife'. Similarly, Bridget stated as she got 'to know the woman and her family there is a lot of growth and learning' and Patrice noted that she was learning through 'experience'. The new graduate midwives were learning and consolidating skills alongside the woman as Samantha described, 'I liked the full range of my skills being used'. Bridget proposed that you 'learn so much from the woman herself and Alice supported this saying 'I learn with the woman'.

Continuity supported learning, for example, Bridget stated 'continuity is amazing, so good for learning' and 'I get to know the woman and their families, there is a lot of growth and learning for me'. Lisbeth also talked about continuity providing learning opportunities across the full scope of practice for a midwife 'I wanted the whole scope' that is providing care throughout pregnancy, birth and the postnatal period. These midwives felt that continuity of carer helped them learn and grow more quickly than the standard transitional support model.

Some midwives were challenged because they were learning, for example, Bridget said she felt it was 'annoying for some women because I am just learning'. She went onto explain that it might take her longer to complete an antenatal visit because she was in her first year of practice and she was consolidating skills.
Hattie felt this was not a problem when she knew the woman 'they understand I am a graduate and in my first year of learning'. For Hattie, the trusting relationship with the woman meant that she understood if it took her longer to complete an antenatal visit, or if she had to look something up. Lisbeth thought this to be a positive of the relationship aspect 'As a young practitioner to be exposed to that emotional vulnerability [of the woman] is probably a really good thing [for learning]'. Lisbeth is referring to the interpersonal relationship that develops when the midwife knows the woman and 'something goes wrong', for example, a fetal death in utero. The new graduates felt that their skills were consolidated through learning and growing in the relationship with the woman.

\section{Having trusting relationships through continuity of care}

The new graduates felt that the development of trusting relationships meant that they could work effectively with women. Hattie stated, 'I just give the information, in that model it is the woman making the decision' indicating that the participants trusted the woman's decisions and choices the woman made about her own care. None of the participants discussed caring for any woman who they felt made potentially unsafe decisions. Robyn talked about 'having more discussions antenatally' when you know the woman, as they have more time available to talk to women in person or on the telephone. Getting to know the woman and spending a lot of time with the woman antenatally enabled the development of a trusting relationship.

The participants also described having more trusting professional relationships with colleagues, for example Christine said 'what I didn't realise was the relationship I would have with the obstetric staff. They felt that the relationships with their medical colleagues were easier because when they needed to discuss a woman with the obstetrician, they were familiar with the woman's background. 'The ones [doctors] I go to, know that I'm generally concerned, they trust my judgment because I know the woman' [Robyn].

The trusting relationship also assisted the woman to accept unexpected or unplanned outcomes. For example, Ness described, 'they [the women] are happy to transfer because of the relationship'. Transfer in this context refers to the woman needing to be referred to an obstetrician. The consultation may result in the woman having to birth in a hospital setting rather than the birth centre or homebirth setting. Some midwives would continue to provide continuity of midwifery care to the woman in collaboration with the obstetrician. Others needed to 'hand over' or transfer all care to the medical team and hospital midwifery staff. Overall, the new graduate midwives reported feeling 'confident' when consulting with their medical colleagues and the women were usually happy to transfer care, if necessary, due to the trusting relationship.

\section{Defining professional boundaries through continuity of care}

Some challenges arose from the relationship in relation to defining professional boundaries. Lisbeth stated you 'really relate to them' [the women] and 'understand them, like you are friends with some of these people'. Hattie reports they become 'part of your life' and 'it becomes like a friendship'. On the other hand, Hattie acknowledged that the 'relationship with the woman is wonderful yet sometimes challenging'. Candice stated 'it's gone beyond a professional relationship to a friendship' and she struggled with this going on to say 'you are not their friend but their carer' and 'ending the relationship can be difficult'. 


\section{The relationship with the group}

The new graduate midwives valued the relationship they had with the small team of midwives they worked alongside - their group. As Lisbeth said 'we could call them anytime day and night [for advice or assistance]'.

\section{Finding support from within the group}

The new graduate midwives valued the support provided by the group. They found support from within the group or pair of midwives, for example, Lisbeth said 'I have been extremely supported by the midwives around me'. Siobhan also stated 'I feel incredibly well supported by all the midwives' and Christine, 'there is always someone around I can ask'. Samantha also talked about 'always having someone around I can ask'. Even when the new graduate midwife was working alone in a stand-alone birth centre or in a woman's home, they had mobile phones to contact someone within the group if needed, for example, Hattie said, 'I would just call or text message them' and this was reassuring for the new graduates.

The use of technology, particularly text messaging, was a form of support as Lisbeth said, 'the day starts with a text message' 'the group makes sure you are feeling ok'. Bridget said 'she can literally call them anytime' and Hattie also said she can 'run almost everything past them'. Siobhan was encouraged to 'call me [the more experienced midwife] in the middle of the night if you want to run something by me'. Gabi said 'I would call or text them anytime'. These new graduates reported feeling well supported and strong professional relationships formed.

Some participants were supported with a specific mentor within the group or found one themselves, for example, Gabi said 'I had a mentor for a month and now we still have a bit of a mentoring relationship going on'. Patrice mentioned how lucky she was to have such good support from one particular midwife in the group and 'if I had gone to another hospital I would not have had that luxury'. These midwives felt more supported in continuity compared with working in the standard transitional support programme, for example Ness said 'I actually found I got more support in a continuity of care model'.

Not all found support from within the group. Patrice mentioned, 'some people [other midwives in the group practice] never put up their hand to help yet expect a lot'. Alice stated that some midwives find providing 'support [to a new graduate] draining and that it will take them away from their own caseload'. Candice also stated 'people are reluctant to relieve' when she had been with a woman for a long time.

Those who had difficulty finding support from within the group found support from the midwifery core staff. A lack of staff was discussed as a problem in terms of receiving enough support. Siobhan found support outside of the group stating, "with staffing the way it is we need to call in the core midwifery staff' as 'we can't get midwives to work in the model'. Samantha found the ward-based midwives helpful 'there are some really good midwives, I specifically look for one, she works nights [night duty] and is a fountain of knowledge'. Samantha was not allocated a mentor or able to find someone in the team to mentor her so she looked elsewhere including her medical colleagues, 'the registrars and residents are really approachable'.

Support was also found in the group meetings that were highly valued by the participants. Hattie described 'weekly meetings' whereas Ness said they had 'monthly meetings'. Christine discussed regular meetings 'at least once a week we meet' and described having a 'big birth centre meeting once a fortnight' with a 'mini-audit' looking at practice. These meetings provided 'professional practice support' with the discussion of 'evidence' to support practice. In addition, the meetings provided emotional support, particularly after an event that the new graduate midwife had not experienced previously. Debriefing was a valuable experience for the new graduate midwife.

Most were appreciative of having a reduced caseload at the beginning of their practice. Christine said 'at the start they only give us two [women] a month' and Bridget 'it really helped having a reduced caseload'. This was not universally appreciated with Samantha reporting frustration with her reduced caseload saying, 'I wasn't given a full caseload at the start, I wanted to feel what it was really like, not be molly coddled'. She went on to say, 'I didn't enjoy my orientation, I wasn't allowed to do anything and I felt like a student again'. However, she did value the support offered to her 'I have got people around me who are really happy to help'. The value of support had a dual role of assisting the new graduate midwife to begin autonomous practice and to sustain the continuity of care model.

\section{Sustaining the continuity of midwifery care model}

A couple of participants perceived the support they received from within the group as sustaining the model of care. Lisbeth stated 'they [other midwives] were very protective because they had never had new graduates working in it' and Siobhan said 'it's about protecting the model [of midwifery care]'. Siobhan referred to the model of care 'as such a precious thing'. The participants, along with the midwives that they worked alongside, wanted to ensure sustainability of the model of care by supporting new entrants. The participants were cautious to only call in another midwife when they really needed them as Lisbeth stated 'I try and call them [the other midwives] in daylight hours' Once again, the participants valued the support that enabled them to sustain the midwifery continuity of care model.

\section{Prepared to work in continuity of midwifery care}

The participants felt they were prepared to work in continuity through their education. Alice stated 'we are introduced to it as students' and Lisbeth 'we learnt about the benefits of it [continuity] and it all just makes sense'. Lisbeth goes on 'at uni I developed a passion for group practice' and 'we're taught from the beginning it's the gold standard of care intuitively it makes sense' (Siobhan). The exposure and education about the benefits of continuity of midwifery care made some of the participants decide before they graduated that was where they wanted to work, 'in my final year I started following a homebirth midwife' (Hattie). Christine said that was 'what I really focused on at uni' and Robyn 'from uni I really wanted to work in those models'. Lisbeth also 'knew that is where I wanted to end up'. Bridget described herself as lucky 'cause in my degree there would have been a dozen students out of 40 who would have jumped at the opportunity'. Siobhan said it was a 'real no-brainer, I had the skills to be able to do it'.

Working in continuity 'consolidated everything you learn at uni' (Lisbeth). When the participants developed a relationship with the woman they described feeling an authenticity in their practice for example, Lisbeth says, 'it makes me a good midwife' and Judy 'I feel like a real midwife'. The new graduate midwives felt they had grown into real midwives who practice across the full scope of midwifery practice. They acknowledged they have been learning through this first or second year of practice alongside the woman and were well supported by the group of midwives. 


\section{Discussion}

In Australia, there are limited numbers of new graduate midwives working in midwifery continuity of care despite midwifery students being prepared to work in this way from their degree. This study explores the experiences of this small group. New graduates highly valued working in this way, especially the relationship with the woman and the relationship with the small group of midwives they worked alongside.

Midwifery continuity of care is highly satisfying for both midwives and women, satisfaction contributes to the sustainability of midwifery continuity of care and the associated benefits for women and newborns (Curtis et al., 2006; Freeman, 2006; Collins et al., 2010; Sullivan et al., 2011). The participants in our study described positive experiences working in these models of care with the development of a relationship with the woman being fundamental. The midwife-mother relationship is a professional relationship developed from the first point of contact and is dependent upon trust and respect and provides job satisfaction (Kirkham, 2010; Stevens and Mc Court, 2002; Homer, 2006). The new graduates in our study felt that working in continuity of care was more satisfying compared to working in a standard transition model where they rotated around different wards on a roster and did not develop a relationship with the woman. This has important implications for long-term retention of staff, especially in the early years after graduation. Providing opportunities for newly graduated midwives to work in continuity of midwifery care may contribute to the job satisfaction of midwives and address staff attrition rates from the profession (Curtis et al., 2006).

Many of our participants described the women they provided care for as 'friends'. Other studies have found women have the same perception, with the midwife described as their 'friend' (Freeman, 2006; Walsh, 1999). The challenge for these new graduate midwives was to maintain a professional relationship with the woman (Nursing and Midwifery Board of Australia, 2010).

The transition from student midwife to practising as a confident registered midwife is challenging and many of the traditional support programmes seem to suit organisational needs rather than developing the confidence of the midwife (Davis et al., 2011). The participants in our study believed they were able to consolidate skills through providing continuity of care. Consolidating skills meant that they could demonstrate their competence and increase their confidence as they got to know the woman. It has been reported that midwives working in one to one midwifery feel more confident in their practice when they know the woman (Page, 2003). Confidence of new graduate midwives has been measured and found to improve at the completion of the first year of practice in accordance with the national competency standards for the midwife (Davis et al., 2011; Australian Nursing and Midwifery Council, 2006). We found that a midwifery continuity of care model provides the opportunity for this group of new graduate midwives to consolidate skills and confidence and work to the full scope of their practice.

Having a trusting relationship with the small group of midwives was highly valued by the participants in our study. The new graduate midwives reported being well supported by the small group of midwives they worked alongside. Other studies have shown that new graduate midwives working in midwifery continuity of care need support from midwives within the midwifery group and, at times, from outside the group (Kensington, 2006; Lennox et al., 2008). Support has been described as mentoring, precepting or clinical supervision (Lennox et al., 2008). Similarly, we found many different forms of support were useful including an orientation period with or without a mentor, support from within the group via text, phone or in person, a reduced caseload (although not for all) and support from outside the group.
Clinical decision making is a challenge for new graduates as they move out of a student role and into a fully qualified role. Newly graduated midwives have reported that any dialogue, either brief encounters such as a corridor conversations or a longer dialogue with their midwifery colleagues, assists clinical decision making (Young, 2012). Our study has shown that these trusting relationships enabled the new graduate midwives to find support from outside of the group, such as corridor conversations with an experienced midwife or consultations with the medical staff.

The new graduates in our study reported that experienced midwives wanted to support the new graduate midwives to sustain midwifery continuity of care. The weekly, fortnightly or ad hoc meetings also provided support and should be considered an essential part of cohesive group practice (Homer et al., 2008). The reflections on practice discussed at the team meetings supported new graduate midwives to make clinical decisions.

In Australia, conscious efforts have been made in the midwifery curricula to prepare students to work in continuity of care models through the inclusion of continuity of care experiences (Australian Nursing and Midwifery Council, 2010; Gray et al., 2012) This study has found that these experiences as students were highly beneficial in preparing midwives to work in continuity of care programmes therefore greater efforts need to be made to embed the continuity of care experience in all midwifery pre-registration programmes.

\section{Conclusion}

Midwifery continuity of care is beneficial to women and newborns. The number of midwifery models providing continuity of care to women is increasing across Australia. Currently, there are very limited numbers of new graduate midwives working in midwifery continuity of care models throughout Australia. The new graduate midwives in this study wanted to work in midwifery continuity and felt prepared to work in this way from their degree. In addition, they were all well supported in one way or another to work autonomously. The findings from this study suggest new graduate midwives learn and grow as midwives when working in continuity of care models and they are well supported in their practice. The findings from this study are limited to Australian midwifery continuity of care models with a small sample. As a qualitative descriptive study there is the potential for further interpretive work (Sandelowski, 2010). Further research is needed to discover why new graduate midwives need to complete a transition support programme or have a certain number of years' experience before working in midwifery continuity.

\section{Conflict of interest}

There are no conflicts of interest.

\section{References}

Australian Government Department of Health and Ageing, 2009. Maternity Services Reform. Commonwealth of Australia, Canberra.

Australian Nursing \& Midwifery Council, 2008. Code of Ethics for midwives in Australia, Nursing and Midwifery Board of Australia (viewed 15th May 2013).

Australian Nursing and Midwifery Council, 2006. National Competency Standards for the Midwife. Nursing and Midwifery Board of Australia, Melbourne (viewed 15 May 2013).

Australian Nursing and Midwifery Council, 2010. Midwives - Standards and Criteira for the Accreditaion of Nursing and Midwifery Courses Leading to Registration, Enrolment, Endorsement and Aurthorisation in Australia. Australian Nursing and Midwifery Council, Dickson ACT.

Avis, M., 2003. Do we need methodological theory to do qualitative research. Qual. Health Res. 13, 995-1004. 
Braun, V., Clarke, V., 2006. Using thematic analysis in psychology. Qual. Res. Psychol. 3, 77-101.

Burns, E., Fenwick, J., Schmied, V., Sheehan, A., 2012. Reflexivity in midwifery reserach: the insider/outsider debate. Midwifery 28, 52-60.

Clements, V., Davis, D., Fenwick, J., 2013. Continuity of care: suporting new graduates to grow into confident practitioners. Int. J. Childbirth 3, page 3.

Collins, C.T., Fereday, J., Pincombe, J., Oster, C., Turnbull, D., 2010. An evaluation of the satisfaction of midwives' working in midwifery group practice. Midwifery 26, 435-441.

Curtis, P., Ball, L., Kirkham, M., 2006. Why do midwives leave? (not) being the kind of midwife you want to be. Br. J. Midwifery 14, 27-31.

Davis, D., Foureur, M., Clements, V., Brodie, P., Herbison, P., 2011. The self reported confidence of newly graduated midwives before and after their first year of practice in Sydney, Australia. Women Birth 25 (3), e1-10.

Fereday, J., Collins, C., Turnbull, D., Pincombe, J., Oster, C., 2009. An evaluation of Midiwfery Group Practice Part II: Women's satisfaction. Women Birth 22, 11-16.

Foster, J., Ashwin, C., 2014. Newly qualified midwive's experiences of preceptorship: a qualitative study. MIDIRS; Midwifery Dig. 24, 151-156.

Freeman, L., 2006. Continuity of carer and partnership: a review of the literature. Women Birth 19, 39-44.

Gray, J.E., Leap, N., Sheehy, A., Homer, C.S.E., 2012. The 'follow-through' experience in three-year Bachelor of Midwifery programs in Australia: a survey of students. Nurse Educ. Pract. 12, 258-263.

Hartz, D., Foureur, M., Tracy, S., 2011. Australian Caseload midwifery: the exception to the rule. Women Birth 178, 1-8.

Hodnett, E.D., 2008. Continuity of caregivers for care during pregnancy and childbirth. Cochrane Database Syst. Rev., issue 4 Art. No.: CD000062, http:/ dx.doi.org/10.1002/14651858.

Hodnett, E.D., Gates, S., Hofmeyr, J.G., Sakala, C., Weston, J., 2011. Continuous support for women during childbirth. Cochrane Database Syst. Rev..

Homer, C., Brodie, P., Leap, N., 2008. Midwifery Continuity of Care. Elsevier Chatswood.

Homer, C., Davis, G., Brodie, P., et al., 2001. Collaboration in maternity care: randomised controlled trial comparing continuity of care with standardised hospital care. Br. J. Obstet. Gynaecol. 108, 16-22.

Homer, C.S.E., 2006. Challenging midwifery care, challenging midwives and challenging the system. Women Birth 19, 79-83.

Hughes, A., Fraser, D., 2011. 'SINK or SWIM': the experience of newly qualified midwives in England. Midwifery 27, 382-386.

Kensington, M., 2006. The faces of mentoring in New Zealand: realities for the new graduate midwife. N.Z. Coll. Midwives J. 35, 7-12.
Kirkham, M., 2010. The Midwife-Mother Relationship. 2nd eds., Palgrave Macmillan, Hampshire.

Lennox, S., Skinner, J., Foureur, M., 2008. Mentorship preceptorship and clinical supervisio: three key processes for supporting midwives. N. Z. Coll. Midwives J. 39, 7-12.

McLachlan, H.L., Forster, D.A., Davey, et al., 2012. Effects of continuity of care by a primary midwife (caseload midwifery) on caesarean section rates in women of low obstetric risk: the COSMOS randomised controlled trial. Br.J. Obstet. Gynaecol. 119 (12), 1483-1492.

Minichiello, V., Sullivan, G., Greenwood, K., Axford, R., 2004. Research Methods for Nursing and Health Science, 2nd edn. Prentice Hall, Frenchs Forest.

New South Wales Health, 2010. Maternity - Towards Normal Birth. New South Wales Health, North Sydney.

Nursing and Midwifery Board of Australia, 2010. A midwife's guide to professional boundaries for midwives. Nursing and Midwifery Board, Melbourne (viewed 16 August 2014). 〈http://www.nursingmidwiferyboard.gov.au/Codes-GuidelinesStatements/Codes-Guidelines.aspx - boundaries $\rangle$.

Page, L., 2003. One-to-one midwifery: restoring the "with woman" relationship in midwifery. J. Midwifery Women's Health 48, 119-125.

Pairman, S., Tracy, S, Thorogood, C, Pincombe, J, 2010. Midwifery: Preparation for Practice, 2nd edn. Elsevier, Chatswood.

Rees, C., 2012. Introduction to Research for Midwives, 3rd edn. Churchill Livingstone, Edinburgh.

Sandall, J., Soltani, H., Gates, S., Shennan, A. \& Devane, D. 2013, Midwife-led continuity models versus other models of care for childbearing women, Cochrane Database Syst. Rev., Issue 8, Art. No.: CD004667, http://dx.doi.org/ $10.1002 / 14651858$.

Sandelowski, M., 2000. Whatever happened to qualitative description? Res. Nurs. Health 23, 334-340.

Sandelowski, M., 2010. What's in a name? Qualitative description revisited. Res. Nurs. Health 33, 77-84.

Saultz, J.W., 2003. Defining and measuring interpersonal continuity of care. Ann. Family Med. 1, 134-142.

Stevens, T., Mc Court, C., 2002. One to one midwifery practice part 3: meaning for midwives. Br. J. Midwifery 10, 111-115.

Sullivan, K., Lock, L., Homer, C.S.E., 2011. Factors that contribute to midwives staying in midwifery: a study in one area health service in New South Wales, Australia. Midwifery 27, 331-335.

Walsh, D., 1999. An ethnographic study of women's experiences of partnership caseload midwifery practice: the professional as a friend. Midwifery 15, $165-176$.

Young, N., 2012. An exploration of clinical decision making among student and newly qualified midwives. Midwifery 28, 824-830. 